\title{
New insights into the pathogenesis and treatment of primary pulmonary hypertension
}

\author{
N Rudarakanchana, R C Trembath, N W Morrell
}

\section{Clinical presentation of primary pulmo- nary hypertension}

Primary pulmonary hypertension $(\mathrm{PPH})$ is defined clinically by a sustained elevation of pulmonary arterial pressure $(>25 \mathrm{~mm} \mathrm{Hg}$ at rest or $>30 \mathrm{~mm} \mathrm{Hg}$ during exercise) without a demonstrable cause. Symptoms of PPH are largely non-specific but may include worsening shortness of breath, chest pain, syncope, fatigue, and peripheral oedema. It is a rare disorder with an estimated incidence of $2-3$ per million per year. ${ }^{1} \mathrm{PPH}$ shows a female bias with a F:M ratio of 2.3:1. The median age at diagnosis is 36 years but it may occur at any age. $\mathrm{PPH}$ is a progressive, often fatal, disease with mean survival from diagnosis of 2.8 years. ${ }^{2}$

The precise molecular mechanisms underlying PPH have hitherto remained elusive. Clues to the aetiology of the disease have been suggested by environmental stimuli associated with the development of severe pulmonary hypertension, pathologically indistinguishable from PPH. The association with appetite suppressants, in particular the fenfluramine/ dexfenfluramine group, ${ }^{3}$ suggested a role of re-uptake inhibition of serotonin. ${ }^{4}$ Severe $\mathrm{PPH}$ may also follow HIV-1 infection, and PPH is associated with autoimmune thyroid disease and the presence of circulating anti- $\mathrm{Ku}$ and antinuclear antibodies. ${ }^{1}$

\section{Cellular pathology of PPH}

Pathologically, PPH is characterised by the obliteration of precapillary pulmonary arteries leading to right ventricular failure. Histologically, small pulmonary arteries show increased wall thickness, distal extension of smooth muscle into normally non-muscular vessels, the formation of a neointima, and plexiform lesions. The nature of the cell type responsible for the intimal obliteration of small pulmonary arteries in PPH has been the subject of considerable debate..$^{5-7}$ The intimal lesions comprise myofibroblast-like cells, and the expression of endothelium specific markers is confined to cells lining the vascular lumen. ${ }^{58}$ Further debate surrounds the composition of the plexiform lesion, ${ }^{9}$ although substantial evidence exists for regarding this lesion as a proliferation of endothelial cells supported by a myofibroblast stroma. $^{510}$ Interestingly, studies have shown that endothelial cells comprising plexiform lesions in $\mathrm{PPH}$ are monoclonal, whereas those in secondary pulmonary hypertension are polyclonal in origin. ${ }^{5}$ Still more controversial is the notion that intraluminal plexiform lesions are directly responsible for the vascular obliteration in PPH. ${ }^{69}$ Ultimately, these controversies may only be resolved with the development of a suitable animal model of PPH or the availability of lung tissue from patients with earlier stages of disease so that the natural history of these lesions can be properly determined.

\section{Contribution of genetic studies}

Familial PPH accounts for at least $6 \%$ of all cases of PPH. Segregation analysis of affected pedigrees reveals an autosomal dominant inheritance with markedly reduced penetrance (10-20\%). ${ }^{11}$ In 1997 a genome wide screen established linkage to a region on chromosome $2 \mathrm{q} 33 .^{12}$ Last year two groups reported that heterozygous mutations of the gene encoding type II bone morphogenic protein receptor (BMPRII) underlie familial PPH. ${ }^{13}{ }^{14}$ More than $72 \%$ of families analysed thus far have shown either a BMPR2 mutation or evidence of linkage to the BMPR2 locus. Furthermore, $26 \%$ of cases of apparently sporadic PPH harbour germline BMPR2 mutations, some of which were transmitted by unaffected parents, while de novo mutation has also been documented..$^{15}{ }^{16}$ The techniques employed in these studies may have failed to detect large gene deletions or rearrangements and thus may have underestimated the true frequency of mutation.

The 46 unique BMPR2 mutations identified so far include splice-site mutation, partial deletions, nonsense, frameshift, and missense. ${ }^{15}$ Mutations occur in the ligand binding, transmembrane and kinase domains, and long intracellular tail of the receptor. The majority of nonsense and frameshift mutations are predicted to cause premature truncation of the gene transcript ( $58 \%$ of all mutations), with nonsense mediated mRNA decay leading to no production of the mutated BMPRII polypeptide. It therefore seems likely that the molecular mechanism for altered BMPRII function involves haploinsufficiency for at least some mutations. A recent study reported complete loss of BMPRII function on in vitro expression of one missense and one frameshift mutation, ${ }^{15}$ but the functional impact of these mutations requires further study in relevant cell types.

\section{Potential role of bone morphogenic proteins in vascular remodelling} Little is known regarding the function of bone morphogenic proteins (BMPs) in the lung. BMPs are the largest group of cytokines within the transforming growth factor $\beta$ superfamily (TGF- $\beta$ ) and were originally identified as molecules regulating growth and differentiation of bone and cartilage. ${ }^{17}$ However, BMPs are known to regulate growth, differentiation, and apoptosis in a diverse number of cell lines including mesenchymal and epithelial cells, ${ }^{17}{ }^{18}$ 
acting as instructive signals during embryogenesis and contributing to the maintenance and repair of adult tissues. ${ }^{19}$ Evidence shows that BMP7 inhibits serum stimulated and growth factor induced proliferation of human aortic smooth muscle cells, ${ }^{19}$ while BMP2 has been shown to inhibit injury induced intimal hyperplasia in a rat carotid artery balloon injury model. ${ }^{20}$ We have recently shown that BMPs fail to suppress proliferation of pulmonary artery SMCs from patients with $\mathrm{PPH} .{ }^{21}$ Disruption of BMP signalling pathways may thus result in failure of a critical antiproliferative/differentiation mechanism in the pulmonary vasculature.

The predilection of the disease process in $\mathrm{PPH}$ for the pulmonary vessels is at first sight surprising, considering the widespread involvement of BMPs during development. However, tissue specificity of the system is dictated by a variety of pre- and post-receptor mechanisms. TGF- $\beta$ superfamily receptors are serine/ threonine kinase receptors and exist constitutively as homodimers in the absence of ligand binding. ${ }^{11}$ BMPRII binds and initiates signalling in response to specific ligands: $\mathrm{BMP} 2$, BMP4, BMP7, GDF5, and GDF6. ${ }^{22}{ }^{23}$ The BMP signal transduction pathway involves receptor heterodimerisation and activation of specific TGF- $\beta$ superfamily signalling proteins known as Smads. BMP signalling is regulated at many different levels-for example, by endogenous inhibitors of BMP binding/ signalling such as Noggin and Chordin, the levels of expression of specific BMPs, the presence of type I and II receptors available for dimerisation, and interactions with other growth signalling pathways such as the mitogen activated protein kinase pathway. ${ }^{24}$ Identification of the BMP signalling pathways specific to pulmonary arterial cells may reveal the basis of pulmonary vascular selectivity in $\mathrm{PPH}$.

The identification of BMPR2 mutations in $\mathrm{PPH}$ provides further evidence for the critical role of the TGF- $\beta$ superfamily in pulmonary vascular disease. Interestingly, mutations in the endoglin gene (a TGF- $\beta$ receptor complex accessory protein) and the putative TGF- $\beta$ type 1 receptor, ALK-1, underlie hereditary haemorrhagic telangiectasia, ${ }^{25}$ a condition frequently complicated by pulmonary arteriovenous malformations. Mutations in ALK-1 may also lead to the development of $\mathrm{PPH}$ in some families with hereditary haemorrhagic telangiectasia. ${ }^{26}$ At first sight it therefore appears paradoxical that mutations in similar pathways may lead to vascular dilation lesions (arteriovenous malformations) on the one hand and vascular obliteration/obstruction on the other $(\mathrm{PPH})$. However, the effects of TGF- $\beta$ on vascular cell differentiation and proliferation are complex, depending on the local vascular context and interactions with additional environmental or genetic factors. ${ }^{27}$ Microsatellite instability leading to somatic acquired mutation in genes regulating apoptosis and the TGF- $\beta$ type II receptor have recently been identified more frequently in plexiform lesions from patients with PPH. Reduced TGF- $\beta$ receptor function may lead to loss of the growth suppressive/differentiation effects of TGF- $\beta$ in some of these lesions.

New insights into the pathogenesis and treatment of PPH

With the discovery of the pivotal role of BMPRII mutations in PPH, we can begin to construct models of pathogenesis. Although familial PPH is characterised by low disease gene penetrance, a recent study has shown that apparently unaffected carriers of the disease gene have abnormally high increases in pulmonary artery pressure on exercise. ${ }^{28}$ This suggests that BMPRII mutations may lead to an abnormal pulmonary vasculature that predisposes to PPH. A "two hit" hypothesis may be considered in which the vascular abnormalities characteristic of $\mathrm{PPH}$ are triggered by accumulation of genetic and/or environmental insults in a susceptible individual. For example, a germline BMPRII mutation in combination with a somatic mutation in the BMP pathway or one of the related pathways regulating cell growth and apoptosis may be sufficient to generate clinical disease. However, environmental "injury" such as the ingestion of appetite suppressants may impose an additional burden predisposing to disease. Acquired somatic mutations in the TGF- $\beta$ type II receptor and Smad 4 are well known associations with certain gastrointestinal cancers. ${ }^{1129}$

Consideration of this model generates several key questions.

- What are the functional consequences of genetic defects in BMPRII in pulmonary vasculature cells?

- What are the effects on downstream signalling and transcription and how do these interact with other key signalling pathways?

- Do somatic mutations contribute to the development of PPH lesions?

- What are the exact mechanisms by which environmental insults result in PPH?

- What is the frequency of $B M P R 2$ mutations in other forms of pulmonary hypertension?

Investigation of these questions will allow us a greater understanding of the mechanisms of pathogenesis of this presently enigmatic disease.

At present $\mathrm{PPH}$ remains a diagnosis of exclusion. Owing, perhaps, to the non-specific nature of its symptoms and the requirement for invasive procedures, the diagnosis of $\mathrm{PPH}$ is often considerably delayed. Genetic analysis for germline BMPRII mutations is a potential diagnostic tool and may be used appropriately to direct genetic counselling and screening of relatives. ${ }^{16}$

Current medical treatment for PPH includes anticoagulation, calcium channel blockers, and continuous intravenous or nebulised prostacyclin analogues. ${ }^{1}$ These measures may improve survival but definitive treatment requires lung or heart-lung transplantation. Phosphodiesterase inhibitors and endothelin receptor antagonists are being assessed as possible treatments. ${ }^{130}$ However, elucidation of the molecular and cellular mechanisms underlying PPH will provide a powerful basis for the 
development of novel therapeutic strategies, including targeted gene therapy, in the treatment of this devastating condition.

1 Gaine SP, Rubin LJ. Primary pulmonary hypertension. Lancet 1998;352:719-25.

2 Rubin LJ. Primary pulmonary hypertension. $N$ Engl f Med 1997;336:111-7.

3 Abenhaim L, Moride Y, Brenot F, et al. Appetitesuppressant drugs and the risk of primary pulmonary hypertension. N Engl f Med 1996;335:609-16.

4 MacLean MR, Herve P, Eddahibi S, et al. 5-hydroxytryptamine and the pulmonary circulation: receptors, transporters and the relevance to pulmonary arterial hypertension. Br f Pharmacol 2000;131:161-8.

5 Yi ES, Kim H, Ahn H, et al. Distribution of obstructive intimal lesions and their cellular phenotypes in chronic pulmonary hypertension. A morphometric and immunohistochemical study. Am $\mathcal{F}$ Respir Crit Care Med 2000;162 $1577-86$

6 Yeager ME, Halley GR, Golpon HA, et al. Microsatellite instability of endothelial cell growth and apoptosis gene within plexiform lesions in primary pulmonary hypertension. Circ Res 2001;88:e2-11

7 Tuder RM, Groves B, Badesch DB, et al. Exuberant endothelial cell growth and elements of inflammation are present in plexiform lesions of pulmonary hypertension. Am f Pathol 1994;144:275-85.

8 Orte C, Polak JM, Haworth SG, et al. Expression of pulmonary vascular angiotensin-converting enzyme in primary and secondary plexiform pulmonary hypertension. $\mathcal{F}$ Pathol 2000;193:379-84.

9 Lee SD, Shroyer KR, Markham NE, et al. Monoclonal endothelial cell proliferation is present in primary but not secondary pulmonary hypertension. F Clin Invest 1998;101: 927-34.

10 Smith P, Heath D, Yacoub MH, et al. The ultrastructure of plexogenic pulmonary arteriopathy. I Pathol 1990;160 $111-21$.

11 Massague J, Blain SW, Lo RS. TGF- $\beta$ signalling in growth control, cancer, and heritable disorders. Cell 2000;103: 295-309.

12 Nichols, WC, Koller, KD, Slovis, B, et al. Localization of the gene for familial primary pulmonary hypertension to chromosome 2q31-32. Nature Gen 1997;15:277-80.

13 Deng Z, Morse JH, Slager SL, et al. Familial primary pulmonary hypertension (gene PPH1) is caused by mutations in the bone morno enic protein receptor-II gene. Am f Hum Genet 2000;67:737-44.

14 The International PPH Consortium, Lane KB, Machado $\mathrm{RD}$, et al. Heterozygous germline mutations in BMPR2, encoding a TGF- $\beta$ receptor, cause familial primary pulmonary hypertension. Nature Gen $2000 ; 26: 81-4$.
15 Machado RD, Pauciulo MW, Thomson JR, et al. BMPR2 haploinsufficiency as the inherited molecular mechanism for primary pulm

16 Thomson JR, Machado RD, Puciulo MW, et al. Sporadic primary pulmonary hypertension is associated with germine mutations of the gene encoding BMPR-II, a receptor of the TGF- $\beta$ family. $\mathscr{F}$ Med Genet $2000 ; 37: 741-5$.

17 Kawabata M, Imamura T, Miyazono K. Signal transduction by bone morphogenic proteins. Cytokine Growth Factor Rev 1998;9:49-61.

18 Sakou T. Bone morphogenic proteins: from basic studies to clinical approaches. Bone 1998;22:591-603.

19 Dorai H, Vukicevic S, Sampath TK. Bone morphogenic protein-7 (OP-1) inhibits smooth muscle cell proliferation and stimulates the expression of markers that are characteristic of SMC phenotype in vitro. 7 Cell Physiol 2000;184:37-45.

20 Nakaoka T, Gonda K, Ogita T, et al. Inhibition of rat vascular smooth muscle cell proliferation in vitro and in vivo by lar smooth muscle cell proliferation in vitro and in vivo by 32 .

21 Morrell NW, Yang X, Upton PD, et al. Altered growth responses of pulmonary artery smooth muscle cells from patients with primary pulmonary hypertension to TGF- $\beta 1$ and bone morphogenic proteins. Circulation 2001; 104: $790-5$.

22 Miyazono, K. TGF- $\beta$ signalling by Smad proteins. Cytokine Growth Factor Rev 2000;11:15-22.

23 Massague J, Chen YG. Controlling TFG- $\beta$ signalling. Genes Devel 2000;14:627-44.

24 Ishida W, Hamamoto T, Kusanagi K. Smad6 is a Smad1/5induced Smad inhibitor. F Biol Chem 2000;275:6075-9.

25 Shovlin CL, Hughes JM, Scott J, et al. Characterization of endoglin and identification of novel mutations in hereditary endoglin and identification of novel mutations in hereditary
hemorrhagic telangiectasia. Am f Hum Genet 1997;61:6879 .

26 Trembath RC, Thomson JR, Machado RD, et al. Clincial and molecular genetic features of pulmonary hypertension in hereditary hemorrhagic telangiectasia. $N$ Engl $f \mathrm{Med}$ 2001; 345:325-34.

27 Schulick AH, Taylor AJ, Zuo W, et al. Overexpression of transforming growth factor beta 1 in arterial endothelium causes hyperplasia, apoptosis, and cartilaginous metaplasia. Proc Natl Acad Sci USA 1998;95;6983-8.

28 Grunig E, Janssen B, Mereles D, et al. Abnormal pulmonary artery pressure response in asymptomatic carriers of primary pulmonary hypertension gene. Circulation 2000; 102:1145-50.

29 Sirard C, Kim S, Mirtsos C, et al. Targeted disruption in murine cells reveals variable requirement for Smad4 in transforming growth factor $\beta$-related signalling. If Biol Chem 2000;275:2063-70.

30 Newman JH, Lane KB. Hypertensive pulmonary vascular disease. Am f Respir Crit Care Med 2000;162:2020-1. 